\section{Reforma psiquiátrica e o Datasus: o uso de um instrumento ou o uso instrumental?}

\author{
Psychiatric reform and Datasus: the use of an instrument or \\ an instrumental use?
}

\section{Lucas Spanemberg*}

* Psiquiatra. Preceptor de Residência, Unidade de Internação Psiquiátrica, Hospital São Lucas, Pontifícia Universidade Católica do Rio Grande do Sul (PUCRS), Porto Alegre, RS. Doutorando, Programa de Pós-Graduação em Psiquiatria, Universidade Federal do Rio Grande do Sul (UFRGS), Porto Alegre, RS. Suporte financeiro: Bolsa de Doutorado, Coordenação de Aperfeiçoamento de Pessoal de Nível Superior (CAPES)

Caro Editor,

Gostaria de tecer alguns comentários sobre o artigo intitulado "A falácia da adequação da cobertura dos Centros de Atenção Psicossocial no estado do Rio Grande do Sul"", recentemente publicado na Revista de Psiquiatria do Rio Grande do Sul.

Em primeiro lugar, é importante salientar o mérito de trabalhos como esse. O tema da atenção em saúde mental tem sido relativamente ignorado nas publicações científicas em psiquiatria no nosso meio quando comparado a outros temas, demonstrando certa negligência dos psiquiatras em relação ao assunto. Por outro lado, tem sido cada vez maior a atuação de nossas entidades representativas (Associação Brasileira de Psiquiatria ${ }^{2}$ e Associação de Psiquiatria do Rio Grande do Sul, por exemplo) em fóruns, debates e discussões sobre o tema da assistência à saúde mental, apontando para uma participação mais atuante dos psiquiatras numa "reforma" da qual estávamos praticamente excluídos.

Contudo, o artigo em questão traz à tona outro tema não menos importante: o uso instrumental dos números e cifras gerados pelos bancos de dados oficiais para a defesa política de uma proposta. Os autores revelam a existência de uma desigualdade importante na oferta de serviços dos Centros de Atenção Psicossocial (CAPS) no Rio Grande do Sul, a despeito da "adequação numérica global" observada no estado. Desconstroem, assim, a tese da boa cobertura dos CAPS no RS. Porém, essa revelação pode ser somente a ponta do iceberg: em que medida podemos confiar na veracidade dos bancos de dados oficiais do Sistema Único de Saúde (SUS)? Serão confiáveis os registros de procedimentos, internações, profissionais no sistema e indicadores de saúde?

Alguns trabalhos têm mostrado que podemos usar as informações do Datasus* como fonte de pesquisa em psiquiatria ${ }^{3}$, sendo esta uma ferramenta válida e útil. Contudo, a existência de informações não significa sua veracidade ou confiabilidade.
Um exemplo de que esses números podem estar equivocados é uma constatação pessoal. Na relação de profissionais ativos publicada pelo Datasus na página do Ministério da Saúde ${ }^{4}$, ainda consto como psiquiatra "ativo" vinculado à "Casa de Saúde Mental NH", sendo que não atendo nessa instituição há quase 2 anos. Da mesma maneira, muitos outros profissionais que não atendem mais na rede ainda têm seus nomes publicados como "ativos", o que pode construir números superfaturados sobre o SUS. Na mesma linha, não são incomuns os relatos de médicos registrados na rede de que os números gerados muitas vezes não correspondem aos executados, uma vez que a quantidade de informações ainda não é acompanhada de um sistema de controle suficientemente complexo e eficaz para gerenciá-las, assim como de recursos humanos capacitados e suficientes para cumprir essa tarefa. Além disso, o uso político de cifras para defender determinadas ações pode mascarar realidades não tão desejáveis quanto pregam suas ideologias originais. Assim, a reforma psiquiátrica têm implicado uma política de desassistência e de fechamento de leitos, sem uma construção adequada de rede alternativa ${ }^{5}$. Quem trabalha com internação psiquiátrica conhece bem essa realidade, pois nos deparamos cotidianamente com a falta de leitos psiquiátricos e a falta de uma rede de atenção adequada para os pacientes do SUS que recebem alta hospitalar.

Por fim, acredito que esse debate apenas se inicia e implica um amadurecimento na construção de um sistema de saúde eficiente e suficiente. As imperfeições e distorções fazem parte desse amadurecimento, mas devem ser sempre consideradas face às limitações dos dados gerados. Se as metodologias de pesquisa não considerarem a baixa confiabilidade desse tipo de informação, podem ser geradoras de dados falsos, inúteis ou até perigosos - tão perigosos quanto o uso político e instrumental de cifras para mascarar um sistema de saúde mental ainda ineficaz e pouco acessível.

\section{Referências}

1. Gonçalves VM, Candiago RH, Saraiva SS, Lobato MI, Belmonte-de-Abreu PS. A falácia da adequação da cobertura dos Centros de Atenção Psicossocial no estado do Rio Grande do Sul. Rev Psiquiatr Rio Gd Sul. 2010;32:16-8.

2. Hetem LA. A clínica da reforma: o que é e o que pode vir a ser. Debates - Psiquiatria Hoje. 2009;1(1):12-5.

3. Candiago RH, Abreu PB. Uso do Datasus para avaliação dos padrões das internações psiquiátricas, Rio Grande do Sul. Rev Saude Publica. 2007;41:821-9.

4. Brasil, Ministério da Saúde. Cadastro Nacional dos Estabelecimentos em Saúde. 2010. http://cnes.datasus.gov.br/Mod_Profissional.asp?VCo_Unidade=4313402230968. Acessado 08 ago 2010.

5. Lejderman F. A falácia da adequação da cobertura dos Centros de Atenção Psicossocial no estado do Rio Grande do Sul: comentário. Rev Psiquiatr Rio Gd Sul. 2010;32:1-2.

* Departamento de Informática do Sistema Único de Saúde, vinculado à Secretaria Executiva do Ministério da Saúde (http://www.datasus.gov.br), acessado em 08/08/2010.

Correspondência:

Lucas Spanemberg, Unidade de Internação Psiquiátrica, HSL/PUCRS, Av. Ipiranga, 6690, 6º andar sul, Jardim Botânico, CEP 90160-090, Porto Alegre, RS, Brasil. Tel. (51) 3320-3041. E-mail: 1spanemberg@yahoo.com.br

Não foram declarados conflitos de interesse associados à publicação desta carta.

Copyright (C) Revista de Psiquiatria do Rio Grande do Sul - APRS

Recebido em 08/08/2010. Aceito em 27/08/2010. 